\title{
MEDIAN (THIRD) OCCIPITAL CONDYLE CAUSING ATLANTOAXIAL INSTABILITY AND MYELOPATHY
}

\author{
Nicandro Figueiredo', Laryssa Brito Moraes ${ }^{2}$, Alexandre Serra ${ }^{3}$, \\ Sérgio Castelo ${ }^{4}$, Douglas Gonsales ${ }^{2}$, Roger Rotta Medeiros ${ }^{3}$
}

Abnormalities of the craniovertebral junction are of great interest not only to anatomists but also to clinicians, because many of these malformations can produce neurological symptoms and death. Median occipital condyle is presented in postmortem anatomic studies, but there is a lack of clinical study regarding this anomaly in the literature ${ }^{1-3}$. Considering the segmental complexities involved in the phyletic and developmental establishment of the normal human craniovertebral articulations, the ocasional ocurrence of anomalous separations, fusions, and intercalated ossicles should not be surprising ${ }^{4}$. One of these manifestations of variant segmentation is the third condyle (basilar tubercle). This structure occurs as a projection on basion (anterior central point) of the foramen magnum. Some incidences are expressed as a simple rounded tubercle, but in more developed cases there is actually an articular facet that receives the tip of the odontoid process forming a true diarthrosis. In a series of 600 skulls, some suggestions of craniovertebral malformations, including a third condyle, was present in 14 per cent $^{5}$. The mamalian apical odontoid element is the phylogenetic equivalent of the proatlas of reptiles. In most members of this vertebrate class this proatlas fuses to the occiput of the skull, whereas in mammals it becomes fused to the atlantal contribution of the odontoid ${ }^{6}$.

We therefore report a case of a patient with median occipital condyle, associated to transverse ligament laxity and atlantoaxial instability (AAI), who had mild symptoms few months before a sudden tetraplegia.

\section{CASE}

A 45-year-old man, Japanese descendant, had a sudden tetraplegia unleashed after a fast ride down a roller coaster. At that instant, the patient stated that he felt that he had a "neck cracking" and at the moment the car stopped he felt syncope for some seconds; faintness; scotoma; neck pain; dyspnea and quadriplegia. He was immediately taken to a local hospital by the paramedics, where he was evaluated, submitted to some exams, like X-ray, CT scan and MRI of the cervical spine. His cervical motion was partially restricted by a rigid cervical brace, he received initial medical care, and started to recover his neurological functions. The family contacted us, and the patient was transferred by airplane to our hospital, two days later. The patient had a history of some episodes of paresthesias affecting his four limbs, about eight months earlier. He also had some previous neck and lumbar pain, restriction of neck movements, constipation and sleeplessness.

Physical examination made in our hospital revealed: tetraparesis (classified as ASIA D), worse on his left side, increased profound reflex on four limbs; hypoesthesia below the neck (about C3 cord level); feet clonus, and bilaterally Babinski's sign.

We immediately installed a halo vest to restrict his cervical motion, and then we completed the study with the CT scan involving the craniovertebral junction.

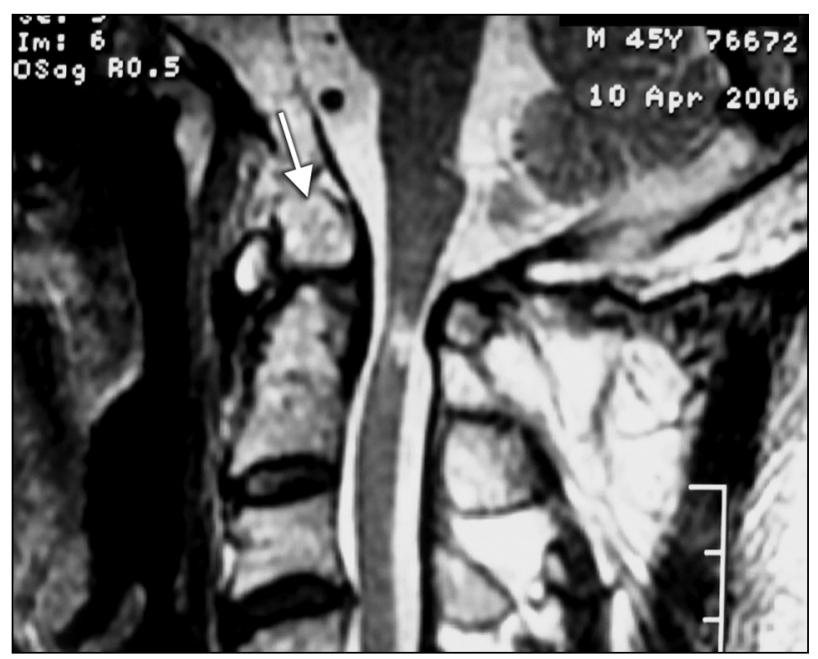

Fig 1. Sagittal T2 MRI of the cervical spine: anomalous bone element at occipital- $\mathrm{Cl}$ transition, the dens is relatively short, the spinal cord was narrowed at C1-2 level, with altered signal, compatible with chronic edema or myelomalacia.

\section{TERCEIRO CÔNDILO OCCIPITAL CAUSANDO INSTABILIDADE ATLANTOAXIAL E MIELOPATIA}

${ }^{1}$ MD, MSc, Professor of Neuroanatomy and Neurosurgery, Federal University of Mato Grosso, Cuiaba MT, Brazil; ${ }^{2}$ Medical-Student, University of Cuiaba, Cuiaba MT, Brazil; ${ }^{3} \mathrm{MD}$, Professor of Neuroanatomy and Neurosurgery, University of Cuiaba, Cuiaba MT, Brazil; ${ }^{4}$ MD, Professor of Neuroradiology, University of Cuiaba, Cuiaba MT, Brazil.

Received 9 August 2007, received in final form 15 October 2007. Accepted 22 November 2007.

Dr. Nicandro Figueiredo - Avenida das Flores 941 / $7^{\text {st }}$ floor / Instituto Neurológico e da Coluna Vertebral - 78043-172 Cuiaba MT - Brasil. E-mail: nicandro2@yahoo.com 


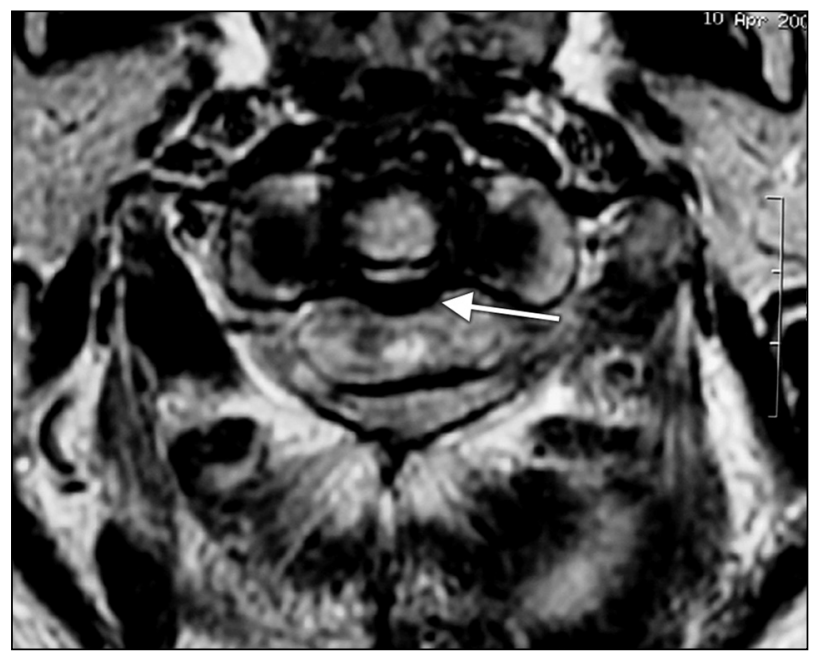

Fig 2. Axial MRI on T2 of C1-C2 level:, show a thick and flaccid transverse ligament, compatible with atlanto-axial chronic instability, the spinal cord was narrowed at C1-2 level, with altered signal, compatible with chronic edema or myelomalacia.

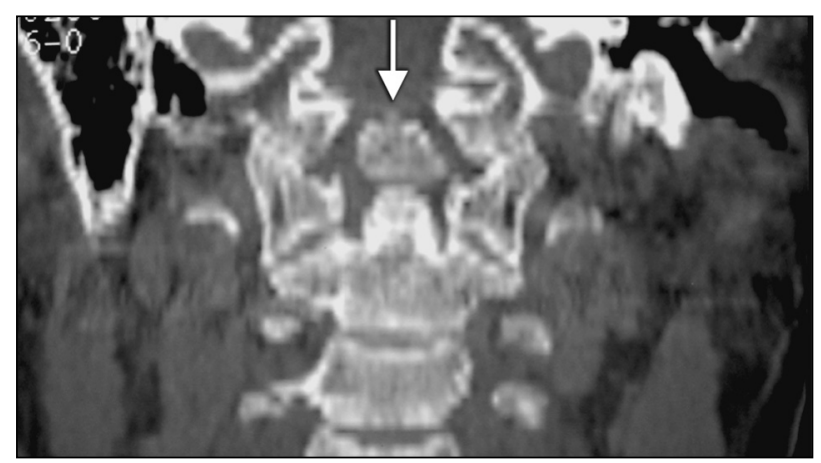

Fig 3. Coronal CT reformation: anomaly formation bone above the dens of $C 2$.

\section{Image study}

The initial X-ray was inconclusive, and the CT scan he brought, including only the levels below $\mathrm{C} 3$, showed no severe abnormality. His MRI showed an anomalous bone element, suggesting initially an odontoid fracture, but with the lack of bone edema on T2 (fat supression image), it could not be an acute fracture line. The dens was relatively short, with a thick and flaccid transverse ligament, compatible with atlanto-axial chronic instability. The spinal cord was narrow at the C1-2 level, with altered signal, compatible with chronic edema or myelomalacia, and not with an acute contusion (Figs 1 and 2).

After the external immobilization, we repeated the CT scan, including the upper cervical levels (C1-2), when we saw the anomalous bone, connected with the occipital bone, confirming the presence of the third occipital condyle, together with odontoid hypoplasia and atlanto-axial chronic instability (Fig 3).

We also ordered a CT scan with angiogram, to better study and plan the surgery, according to the osseous-vascular anatomy.

The patient was transferred to the intensive care ward of our hospital, and we immediately installed a halo vest to restrict his cervical motion, and then we completed the study with the CT scan involving the craniovertebral junction. Then, we analyzed carefully all the images and when we confirmed the diagnosis of the third condyle and AAI, we discussed the case with the patient, and proposed the surgery, mainly because of the craniovertebral malformation and the ligamentous instability.

One month later, we performed a Cl-2 posterior screw-rod fixation ${ }^{7}$ and removed the central part of the posterior arc of $\mathrm{C} 1$ to decompress the canal, with the patient in prone position, under general anesthesia, and intraoperative neuromonitoring (SSEP). We introduced two screws at the lateral mass of atlas, and two more at the pedicle of the axis. Because the $C 2$ root was too close to the lateral mass of $\mathrm{Cl}$, and the space between $\mathrm{C} 1$ and $\mathrm{C} 2$ was too narrow, we had to cut the nerve bilaterally. We took autograft from his iliac bone, and we added it at the C1-2 posterior area for bone fusion.

The patient had excellent recovery, and was discharged from the hospital three days later, wearing a cervico-thoracic brace (Minerva) for 20 days. He resumed his previous usual activities about 45 days after surgery, and he wore a Philadelphia collar for 3 months after surgery. He was followed clinically and radiologically for 6 months, with X-ray and CT scan of the cervical region, and he had excellent clinical and radiological results. He still has some numbness in his right hand, increased profound reflex of four limbs, but he's working and driving by himself.

\section{DISCUSSION}

Atlantoaxial instability may result for many reasons, including hypoplasia of the odontoid process and from laxity of the transverse ligament ${ }^{8}$. The patient we described, had a large third occipital condyle, associated with a hypoplastic odontoid process and laxity of the transverse ligament, according to the exams. These abnormalities resulted in AAI, which caused a mild chronic spinal cord impingement, and a sudden cord lesion when he was going down fast on the roller coaster.

Atlantoaxial subluxation (AAS) is defined as the situation in which the atlas is unstable relative to the axis due to the disruption or insufficiency of the ligamentous complex of the atlantoaxial joint. This pathogenesis has many causes, including congenital diseases. The cause of congenital craniovertebral junction varies. In patients with C1-2 subluxation, what probably transiently happened to our patient, the condition is likely related to ligamentous laxity. Osseous malformation of the dens region may be accounted for abnormal ligamentous laxity due to disturbances in the blood supply to the developing bone as a result of inordinate mobility ${ }^{9,10}$. In contrast, trauma is a relatively uncommon cause of such instability, and the pathomechanics are reported to be due to flexion, distraction and rotation ${ }^{11-15}$. Miyamoto et al described a rare case of AAS that occurred with a professional rugby athlete whose mechanism was in a hiperflexion manner ${ }^{16}$. 
Kotil et al.' also reported a rare case of a 40-year-old woman presenting myelopathy related to condylus occipitalis located in the anterior foramen magnum region. They performed a posterior decompression without fusion, which they concluded not to be effective.

The C1-2 posterior screw for AAI has several advantages include the following: it produces high fusion rates; it allows intraoperative direct reduction, if necessary; C2 pedicle screws provide a higher margin of safety and increased flexibility in altered anatomy; it does not require halo immmobilization; it requires only a small incision with minimal dissection; it also avoids dangerous sublaminar wire passage $e^{7,17,18}$.

In conclusion, we have reported a rare case of an adult who had a sudden tetraplegia during a roller coaster ride, probably related to an AAI due to transverse ligamentous laxity, associated to a congenital malformation of the craniovertebral junction, a median occipital condyle. The patient had a good neurological recovery. He was initially immobilized in a halo device, and submitted to $\mathrm{Cl}-2$ posterior screw-rod fixation, with an excellent result.

Acknowledgments - We would like to thank CEDIC (Centro de Medicina Diagnóstica), which provided the main images for this paper, as well as Mr. John Hall for his translation of the text.

\section{REFERENCES}

1. Kotil K, Kalayci M. Ventral cervicomedullary junction compression secondary to condylus occipitalis (median occipital condyle), a rare entity. J Spinal Disord Tech 2005;18:382-384.
2. Prasada Rao PVV. Median (third) occipital condyle: case report. Clin Anat 2002;15:148-151.

3. Ludinghausen M, Schindler G, Kageyama I, Pomaroli A. The third occipital condyle, a constituent part of a median occipito-atlanto-odontoid joint: a case report. Surg Radiol Anat 2002;24:71-76.

4. Parke WW. Development of the spine. In Rothman-Simeone (Ed). The Spine. Philadelphia: Saunders 1999:3-27.

5. Lang J. Clinical anatomy of the head. Berlin: Springer-Verlag, 1983.

6. Sensing EC. The origin of the vertebral column in deermouse, Peromyscus maniculatus rufinus. Anat Rec 1943;86:123-141.

7. Harms J, Melcher RP. Posterior C1-2 fusion with polyaxial screw and rod fixation. Spine 2001;26:2467-2471.

8. Shaffrey CI, Chenelle AG, Abel MF, Menezes AH, Wiggins GC. Anatomy and physiology of congenital spinal lesions. In Benzel EC (Ed). Spine surgery: techniques, complication avoidance, and management. $2^{\text {nd }}$ Ed. Amsterdam: Elsevier 2005:61-87.

9. Crockard HA, Stevens JM. Craniovertebral junction anomalies in inherited disorders: part of the syndrome or caused by the disorder? Eur J Pediatr 1995;154:504-512.

10. Stevens JM, Kendall BE, Crockard HA, Ransford A. The odontoid process in Morquio-Brailsford's disease: the effects of occipitocervical fusuion. J Bone Joint Surg Br 1991;73:851-858.

11. Huang CI, Chen IH, Lee LS. Traumatic atlantoaxial distractive instability: case report. J Trauma 1994;36:599-600.

12. Carrol EA, Gordon B, Sweeney CA, et al. Traumatic atlantoaxial distractive injury: case report. Spine 2001;26:454-457.

13. Fielding JW, Hawkins RJ. Atlanto-axial rotatory fixation. J Bone Joint Surg Am 1977;59:37-44.

14. Moore KR, Frank EH. Traumatic atlantoaxial rotatory subluxation and dislocation. Spine 1995;20:1928-1930.

15. Wise JJ, Cheney R, Fishgrund J. Traumatic bilateral rotatory dislocation of the atlanto-axial joints: a case report and review of the literature. J Spinal Disord 1997;10:451-453.

16. Miyamoto H, Doita M, Kotaro $\mathrm{N}$ et al. Traumatic anterior atlantoaxial subluxation occurring in a professional rugby athlete: case report and review of literature related to atlantoaxial injuries in sports activities. Spine 2004;29:61-64.

17. Melcher RP, Harms J. C1-2 posterior screw-rod fixation. In Bradford DS, Zdeblick TA (Eds). The spine. $2^{\text {nd }}$ Ed. Lippincott Williams \& Wilkins 2004:129-145.

18. Xiang-Ling Ma, Qing-Shui Yin, Zeng-Hui Wu et al. Anatomic considerations for the pedicle screw placement in the first vertebra. Spine 2005; 30:1519-1523. 